\title{
ATENDIMENTO EDUCACIONAL: EXPERIÊNCIA DE INCLUSÃO SOCIAL DE UM ESTUDANTE COM DEFICIÊNCIA INTELECTUAL
}

Ana Virginia Isiano Lima ${ }^{1}$, Ana Mayra Samuel Silva ${ }^{1}$, Denner Dias Barros ${ }^{2}$, Janiele de Souza Santos ${ }^{2}$, Danielle Aparecida do Nascimento Santos ${ }^{3}$, Elisa Tomoe Moriya Schlünzen ${ }^{3}$

Universidade Estadual Paulista Júlio de Mesquita Filho - UNESP. ${ }^{1}$ Curso de Pedagogia, Presidente Prudente - SP. ${ }^{2}$ Curso de Matemática, Presidente Prudente - SP. ${ }^{3}$ Doutorado em Educação, Presidente Prudente - SP. E-mail: anaisianolima@gmail.com

\section{RESUMO}

O "Centro de Promoção para Inclusão Digital, Escolar e Social" (CPIDES) atua na inclusão digital, educacional e social de Estudantes Público Alvo da Educação Especial (EPAEE). Vinculado à Universidade Estadual Paulista "Júlio de Mesquita Filho" - Faculdade de Ciências e Tecnologia FCT/UNESP de Presidente Prudente/SP, os membros do Grupo de Pesquisa "Ambientes Potencializadores para Inclusão" (API) (pesquisadores e estudantes) desenvolvem estudos sobre Educação Especial e Inclusiva, acessibilidade e estratégias pedagógicas e metodológicas com o intuito de incluir estudantes com perfil destinado à Educação Especial. Para tanto, são realizados atendimentos educacionais com uso das Tecnologias Digitais de Informação e Comunicação e recursos pedagógicos acessíveis. No presente trabalho apresentaremos 0 atendimento educacional realizado junto a um estudante com Deficiência Intelectual (DI). Assim, serão apresentados os resultados parciais dos atendimentos realizados com 0 estudante, contextualizando teoricamente com as concepções de autores sobre métodos de alfabetização, que tem caracterizado a sua inclusão social.

Palavras-chave: Deficiência Intelectual, Atendimento, Alfabetização, Aprendizagem, Inclusão.

\section{EDUCATIONAL ASSISTANCE: EXPERIENCE OF SOCIAL INCLUSION OFA STUDENT WITH INTELLECTUAL DISABILITY}

\begin{abstract}
The "Promotion Center for Digital Inclusion, Social and School" (CPIDES) operates in digital, educational and social inclusion of Target Audience Students in Special Education (TASSE). Linked to the Universidade Estadual Paulista "Júlio de Mesquita Filho" - Faculty of Science and Technology FCT / UNESP Presidente Prudente / SP, the members of the Research Group "Environments enhancers for Inclusion" (API) (researchers and students) develop studies on Education special and Inclusive, accessibility and pedagogical and methodological strategies in order to include students with special Education for the profile. To this end, educational services are provided using the Digital Information and Communication Technologies and accessible educational resources. In this paper we present the educational services conducted with a student with Intellectual Disabilities (ID). Thus, the partial results of the assessments with the student will be presented with theoretically contextualizing the concepts of authors on literacy methods that have characterized their social inclusion.
\end{abstract}

Keywords: Intellectual Disability, Care, Literacy, Learning, Inclusion. 


\section{INTRODUÇÃO}

A Política Nacional de Educação Especial na Perspectiva da Educação Inclusiva (2007) inaugura no cenário brasileiro um avanço educacional fundamentado na construção de sistemas educacionais formais inclusivos, por meio da organização da escola comum em conjunto com a Educação Especial.

A partir dessa política, revelam-se importantes mudanças estruturais da Educação Básica, que deve atender a todas especificidades dos estudantes em termos não só de acesso à escolarização, mas de oportunidades de aprendizado e de desenvolvimento de seus potenciais, por meio da adoção de novas práticas pedagógicas.

Diante dessas perspectivas, o intuito de promover a inclusão digital, educacional e social de Estudantes Público Alvo da Educação Especial (EPAEE) permeia as atividades desenvolvidas no CPIDES da Faculdade de Ciências e Tecnologia FCT/Unesp de Presidente Prudente/SP. Os estudantes de licenciatura da instituição, vinculados a projetos de extensão e pesquisa institucionais e nacionais realizam atendimentos educacionais destinados a estudantes diagnosticados com deficiências e transtornos globais do desenvolvimento. Os atendimentos são direcionados de forma a permitir o afloramento das potencialidades dos EPAEE, utilizando recursos tecnológicos para a abordagem de temas voltados ao interesse do estudante, com vistas à sua inclusão social e educacional.

Assim, os recursos pedagógicos acessíveis são usados para as atividades construcionistas, contextualizadas e significativas, de forma que as atividades permitam abordar os interesses do estudante. Além disso, dependendo da deficiência do estudante, são selecionados recursos de acessibilidade, para permitir a sua mobilidade, orientação e aprendizagem.

Com esses recursos e o planejamento de atividades que partem do interesse dos estudantes, os atendimentos são realizados em um laboratório de informática e em uma Sala de Recursos Multifuncionais (SRM), que é um ambiente dotado de equipamentos pedagógicos e tecnológicos, mobiliários e materiais didáticos, a fim propiciar a oferta do Atendimento Educacional Especializado (AEE).

O AEE pode ser caracterizado como um serviço de educação especial que "[...] identifica, elabora e organiza recursos pedagógicos e de acessibilidades, que eliminem as barreiras para a plena participação dos alunos, considerando suas necessidades específicas" (SEESP/ MEC, 2008). No CPIDES os atendimentos realizados são similares ao AEE.

Nos atendimentos educacionais, além da utilização dos recursos pedagógicos e digitais da SRM, no laboratório são usados Objetos Educacionais que visam trabalhar conceitos de forma 
lúdica, com atividades escritas, jogos, vídeos, entre outras, a fim de desenvolver as potencialidades dos estudantes e minimizar suas dificuldades motoras, sensoriais ou intelectuais, contribuindo para a aprendizagem dos estudantes. Conforme Tarouco (2003) os Objetos Educacionais são recursos suplementares ao processo de aprendizagem, que podem ser utilizados para apoiar a aprendizagem.

Desse modo desenvolvemos um atendimento semanal com um estudante diagnosticado com Deficiência Intelectual (DI). O estudante atendido tem 21 anos e frequentou a escola até o terceiro ano do Ensino Fundamental. Atualmente frequenta a Associação de Pais e Amigos dos Excepcionais (APAE) e tem grande interesse de ser alfabetizado. A definição de Deficiência Intelectual (DI) tem como base os parâmetros inerentes aos manuais publicados pela AAIDD (Associação Americana de Deficiência Intelectual e de Desenvolvimento - em tradução livre) que caracteriza a Deficiência Intelectual como uma deficiência caracterizada por limitações significativas tanto no funcionamento intelectual como no comportamento adaptativo, que abrange as habilidades práticas e sociais, origina-se antes dos 18 anos de idade.

A inclusão de pessoas com DI parece ser um grande desafio, isso porque o estudando com DI é um nó para a educação regular, devido a sua complexidade de aprendizagem, dificuldade de diagnóstico, ceticismo ao desenvolvimento desse estudante e pouco conhecimento sobre um trabalho pedagógico que de fato promova aprendizagem significativa. Nesse direcionamento, é preciso buscar espaços inclusivos e metodologias que busquem um desenvolvimento global do indivíduo. Desse modo, abordaremos os atendimentos educacionais realizados com o intuito de auxiliar um estudante diagnosticado com DI no processo de alfabetização.

Com o objetivo do atendimento previamente determinado, trabalhamos com o desenvolvimento e a superação das suas limitações intelectuais, permitindo a saída de uma posição passiva e automatizada diante da aprendizagem para o acesso e apropriação ativa do próprio saber, ou seja, desenvolvimento da autonomia intelectual.

$\mathrm{O}$ atendimento para o estudante com DI deve privilegiar o desenvolvimento e a superação daquilo que lhe é limitado, que permita a saída de uma posição passiva e automatizada diante da aprendizagem para o acesso e apropriação ativa do próprio saber, ou seja, desenvolvimento da autonomia intelectual. $\mathrm{O}$ estudante citado tem grande interesse em ser alfabetizado, deste modo com a alfabetização esperamos que o estudante alcance sua inclusão escolar e social.

Sendo a inclusão educacional de pessoas com DI e especialmente a aprendizagem da alfabetização para esse público um grande desafio, isso porque o estudante com DI faz com que a escola repense o seu currículo e as práticas de ensino, uma vez que para esse público não há 
possibilidades de aprendizagens mecânicas, os atendimentos educacionais privilegiam a criação de situações de aprendizagens que tenham embasamento nas atividades vividas pelo estudante, que são capazes de mobilizar seu raciocínio.

\section{DESENVOLVIMENTO: METODOLOGIA E PROCEDIMENTOS PRÁTICOS}

Para desenvolver as atividades de ensino, pesquisa e extensão, o grupo de pesquisa API tem autorização do Comitê de Ética em Pesquisa (CEP), cujo protocolo de aprovação é 106/2009.

Para atender ao exposto pelo CEP, antes de iniciar os atendimentos realizamos entrevistas estruturadas com os responsáveis dos estudantes para levantamento de informações que irão nortear a elaboração do plano de atendimentos, considerando prioritariamente os interesses de cada estudante e verificando a necessidade de uso de recursos de acessibilidade. Além de permitir identificar os interesses dos estudantes, a coleta de dados das entrevistas permite verificar as potencialidades de cada estudante, mas também as suas dificuldades.

Após a entrevista é realizado o agendamento dos atendimentos, com cronograma semestral definido (dias e horários). Os atendimentos tem duração de uma a duas horas semanais.

Concomitantemente à realização dos atendimentos é feito levantamento bibliográfico sobre as características e especificidades que devem ser exploradas no ensino para os EPAEE em livros, artigos científicos e sites especializados no assunto. Além disso, são pesquisados materiais relacionados aos conteúdos escolares que podem ser trabalhados com esses estudantes.

Durante os acompanhamentos realizamos a escolha de recursos pedagógicos acessíveis e objetos educacionais a serem utilizados, mediante o objetivo das atividades. As atividades são aplicadas mediante planos de intervenção em que são eleitos temas geradores a partir das preocupações e interesses dos estudantes. A partir disso desenvolvemos trabalhos com projetos, que conforme Segundo Hernandéz e Ventura (1998), é entendido como uma oportunidade onde os alunos percebem que o conhecimento não é exclusividade de determinada disciplina. A articulação dos conhecimentos é objetivo fundamental deste tipo de projeto, uma vez que rompe com essa forma rígida de enquadrar os conteúdos.

Como trabalhamos na perspectiva do trabalho com projetos as atividades são dinâmicas, e para isso precisamos de diferentes recursos como jogos educativos, atividades de escrita e leitura, trabalhos manuais, entre outros. Para a realização das atividades com os EPAEE, além do direcionamento da pesquisa e estudo bibliográfico, os bolsistas contam com formação contextualizada quinzenalmente, onde temas de Educação Especial e Inclusiva e Tecnologias na Educação são abordados. Essa formação tem a finalidade de proporcionar o desenvolvimento de 
práticas e métodos que favoreçam a criação de um ambiente Construcionista, Contextualizado e Significativo, que segundo Schlünzen (2000, p. 82):

É um ambiente favorável que desperta o interesse do aluno e o motiva a explorar, a pesquisar, a descrever, a refletir, a depurar as suas ideias. [...] As informações que são significativas para o aluno podem ser transformadas em conhecimento [...] O aluno consegue descobrir a relação com tudo que está aprendendo, a partir de seus interesses individuais dentro do seu contexto.

O professor que atende o estudante com DI "deve propor atividades que contribuam para a aprendizagem de conceitos, além de propor situações vivenciais que possibilitem esse aluno organizar o seu pensamento". (GOMES; POULIN; FIGUEIREDO, 2010, p.8). Em relação ao aprendizado da leitura e da escrita os estudantes com DI vivenciam processos cognitivos semelhantes aos das crianças que não possuem deficiência. Conforme Falconi e Silva $(2010$, p.15) "no decorrer do processo de construção da escrita, as crianças descobrem as propriedades do sistema alfabético e, a partir da compreensão de como funciona o código linguístico, elas aprender a ler e a escrever".

Nos primeiros atendimentos, para o desenvolvimento da aprendizagem do alfabeto, as palavras trabalhadas tinham relação com o universo do estudante e com seus interesses. Freire (1987, p.6) relata que "essas palavras, oriundas do próprio universo vocabular do alfabetizando, uma vez transfiguradas pela crítica, a ele retornam em ação transformadora do mundo". Durante os atendimentos foi desenvolvido com o estudante um trabalho de conhecimento das letras do alfabeto, relacionando com palavras e figuras que ele conhecia, além disso, utilizamos livros que permitiram que o estudante contextualiza-se as letras aprendidas.

Através da alfabetização do estudante espera-se sua inclusão social, com o intuito de que o estudante consiga realizar atividades simples de seu cotidiano, promovendo sua autonomia em ações que realiza.

\section{RESULTADOS}

A partir das atividades de intervenção resultados preliminares já são observados. Conforme Falconi e Silva (2010, p.17) durante a avaliação "os registros dos alunos expressam o nível da evolução em que elas se encontram, desde a escrita sem valor representativo até a escrita alfabética".

Nos atendimentos iniciais o estudante não reconhecia todas as letras do alfabeto e confundia as letras de imprensa e cursiva. A partir das intervenções realizamos atividades com a letra de imprensa, com o intuito de que o estudante reconhecesse as letras e relacionasse com 
palavras que utiliza em seu cotidiano. Além dos atendimentos enviamos atividades complementares, para que o estudante fizesse na sua casa. Constatamos uma evolução do estudante que tinha dificuldade em reconhecer as letras e relacioná-las com palavras ou figuras. Com as intervenções ele realiza a maioria das atividades de forma espontânea e sem auxílio.

A intervenção pedagógica fez com que houvesse avanços significativos, considerando que o estudante não reconhecia as letras do alfabeto, confundia o traçado e não relacionava as letras com as palavras. . Ainda estamos realizando atendimentos com a finalidade de que o estudante se desenvolva na alfabetização e construa seu conhecimento.

\section{DISCUSSÃO}

Os atendimentos devem ser realizados de forma que as particularidades dos estudantes, para além de sua condição cognitiva, sejam abordadas. Ao considerar as especificidades cognitivas do estudante, observamos a relação que, mediante os atendimentos, o estudante tem estabelecido com o conhecimento que promove sua autonomia intelectual.

Diante disso, o estudante tem avançado na aprendizagem da alfabetização, mas também em diferentes áreas como a afetividade que estabelece nos atendimentos e a interação. Isso é possível, pois respeitamos as suas especificidades, buscando estabelecer situações que favoreçam o seu desenvolvimento global e que estimulem o seu desenvolvimento cognitivo, dentro dos seus limites, objetivando também eliminar as barreiras que dificultam a sua aprendizagem.

\section{CONCLUSÃO}

A inclusão perpassa por todas as dimensões da vida em sociedade e escolar. De acordo com Passerino e Montardo (2007,p. 5)

É o processo estabelecido dentro de uma sociedade mais ampla que busca satisfazer necessidades relacionadas com qualidade de vida, desenvolvimento humano, autonomia de renda e equidade de oportunidades e direitos para os indivíduos e grupos sociais que em alguma etapa da sua vida encontram-se em situação de desvantagem com relação a outros membros da sociedade.

Nesse sentido, nos atendimentos realizados para o desenvolvimento da autonomia do estudante, observamos avanços significativos em atividades que antes eram realizadas com auxílio e que a partir das intervenções o estudante realiza de forma autônoma.

Ainda estamos realizando atendimentos com a finalidade de que o estudante leia e escreva sem auxílio, desenvolvendo ainda mais a sua autonomia e independência. Com a aquisição da leitura e da escrita esperamos que o estudante se desenvolva e seja, de fato, incluído socialmente. 


\section{REFERÊNCIAS}

Associação Americana sobre Deficiência Intelectual e Desenvolvimento (AAIDD). Disponível em: < http://aaidd.org/home>.

BRASIL: Ministério da Educação. Secretaria de Educação Especial. Política Nacional de Educação Especial na perspectiva da Educação Inclusiva. Brasília: MEC/SEESP, 2007.

BRASIL: Ministério da Educação. Secretaria da Educação Especial. Atendimento Educacional Especializado: Deficiência Física. Brasília: MEC/SEESP, 2008.

FALCONI, Eliane Regina Moreno; SILVA, Natalie Aparecida Stuparo. Aspectos biopsicossociais das pessoas com Deficiência Intelectual. 2010.

FREIRE, Paulo. Pedagogia da Autonomia: Saberes Necessários À Prática Educativa. São Paulo: Paz e Terra, 1996.

GOMES, A. L. L. V; POULIN. J; FIGUEIREDO, R. V. A Educação Especial na Perspectiva da Inclusão Escolar: o atendimento educacional especializado para alunos com deficiência intelectual. Brasília: Ministério da Educação, Secretaria de Educação Especial; Fortaleza: Universidade Federal do Ceará, 2010.

Hernandez, F. \& Ventura, M. (1998). A organização do currículo por projetos de trabalho: O conhecimento é um caleidoscópio. 5a Edição, Porto Alegre: Artmed.

PASSERINO, Liliana Maria; MONTARDO, Sandra Portella. Inclusão social via acessibilidade digital: Proposta de inclusão digital para Pessoas com Necessidades Especiais. 2007. Disponível em: www.compos.com.br/e-compos. Acesso em: 07 ago 2014.

SCHUlÜZEN, E. T. M. Mudanças nas Práticas Pedagógicas do Professor: Criando um Ambiente Construcionista, Contextualizado e Significativo para Crianças com Necessidades Especiais Físicas. 2000. 212 f. Dissertação (Doutorado em Educação) - Pontifícia Universidade Católica, São Paulo, 2000.

TAROUCO, L.M.R.; FABRE, M.-C. J. M.; TAMUSIUNAS, F.R. Reusabilidade de objetos de aprendizagem, Novas Tecnologias na Educação. 2003. Disponível em: <http://www.cinted.ufrgs.br/renote/fev2003/artigos/marie_reusabilidade.pdf >. Acesso em: 06 ago 2014. 